\title{
ФРАКТУРЫ ЭМАЛИ (CRAZELINES): ВМЕШИВАТЬСЯ ИЛИ МОНИТОРИТЬ?
}

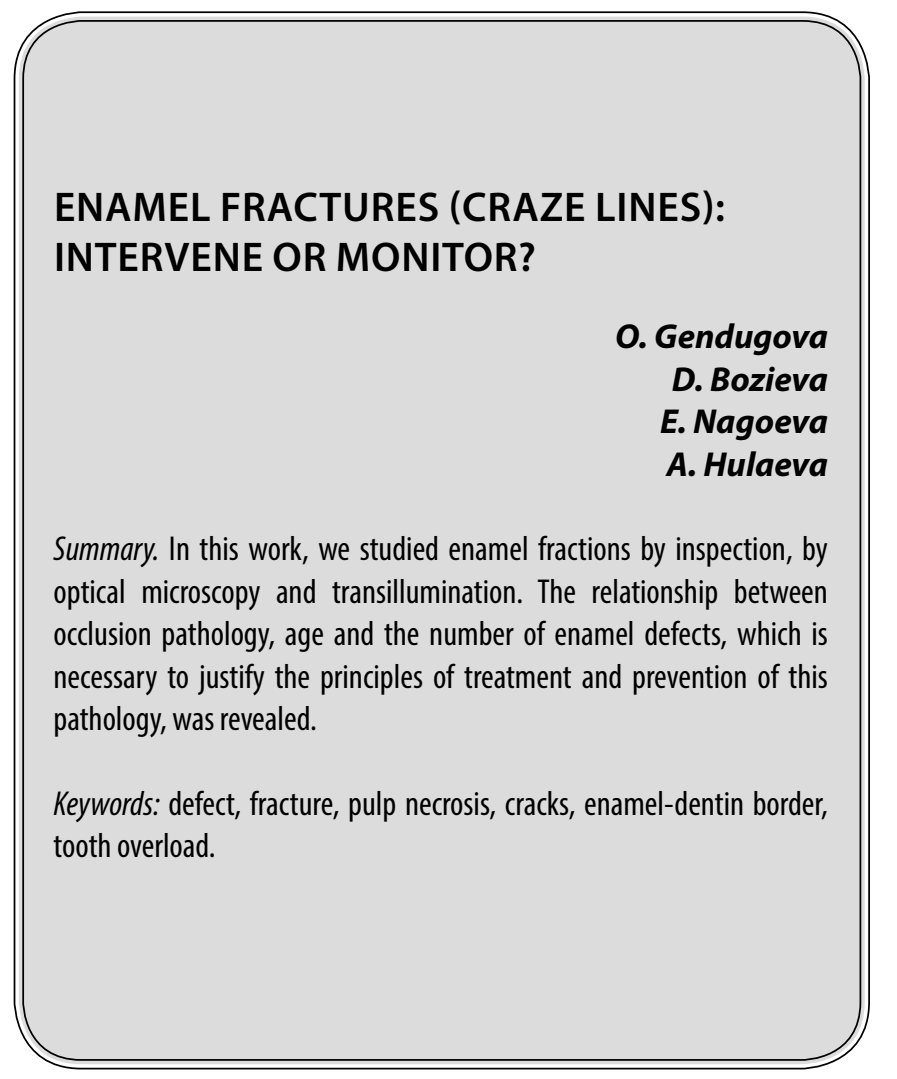

\section{Введение}

$\Phi$ рактуры в структурах зуба - это неполные переломы без разделения твердых тканей. Они бывают вертикальные, горизонтальные и косые. Когда они локализуются в пределах эмали и не продолжаются в дентин, это не оказывает неблагоприятного влияния на функциональный прогноз зуба. Как известно, такие трещины - это предшественники «синдрома треснувшего зуба», поэтому их ранняя диагностика является главной задачей профилактики дальнейших осложнений.

Чем опасны эти трещины? В микроскопически линейных дефектах со временем начинается микробная инвазия, сначала в межпризменные пространства, а со времени может достичь эмалево-дентинного соединения. Могут развиться грозные осложнения вплоть до некроза пульпы, поскольку трещины обеспечивают прямую дорогу бактериям по системе дентинных канальцев в пульпу. А со временем возможен полный перелом, что послужит причиной удаления зуба.
Гендугова Оксана Мухарбиевна

К.м.н., доцент, Кабардино-Балкарский Государственный Университет им. Х.М. Бербекова oksistom@mail.ru

Бозиева Джамиля Султановна Ассистент, Кабардино-Балкарский Государственный Университет им. Х.М. Бербекова dok132813@gmail.com

Нагоева Эльянора Анатольевна Ассистент, Кабардино-Балкарский Государственный Университет им. Х. М. Бербекова ertana1985@mail.ru

Хулаева Аминат Ибрагимовна

Ассистент, Кабардино-Балкарский Государственный университет им. Х.М. Бербекова aminahulaeva1996@mail.ru

Аннотация. В данной работе провели исследование фрактур эмали спомощью осмотра, методом оптической микроскопии и трансиллюминации. Выявили взаимосвязь патологии прикуса, возраста и количества дефектов эмали, что необходимо для обоснования принципов лечения и профилактики данной патологии.

Ключевые слова: дефект, перелом, некроз пульпы, трещины, перегрузка зубов, эмалево-дентинная граница.

Трещины эмали, как правило, остаются незамеченными пациентами и обнаруживаются стоматологами при комплексном плановом обследовании зубов. И чаще всего они диагностируются во фронтальном отделе (83\% случаев) Рис. 1, нежели в боковом сегменте.

\section{Шель исслеАования}

Выявление особенностей корреляции между сопутствующей ортодонтической патологии, возрастом пациентов и наличием дефектов эмали.

\section{Материал и методы \\ исслеАования}

Нами были обследованы 62 пациента, обратившиеся в клинику за плановой терапевтической помощью на предмет наличия трещин эмали. Возраст пациентов варьировал от 19 до 58 лет.

Для исследования фрактур эмали применяли различные технологические приемы: 


\begin{tabular}{|l|l|l|l|l|}
\hline Группа обследуемых & Всего & Нарушение окклюзии & Трещина 1-2 зубов & $\begin{array}{l}\text { Множественные Тре- } \\
\text { щины эмали }\end{array}$ \\
\hline До 30 лет & 35 & $61 \%$ & $17 \%$ & $83 \%$ \\
\hline После 30 лет & 27 & $87 \%$ & $0 \%$ & $100 \%$ \\
\hline
\end{tabular}

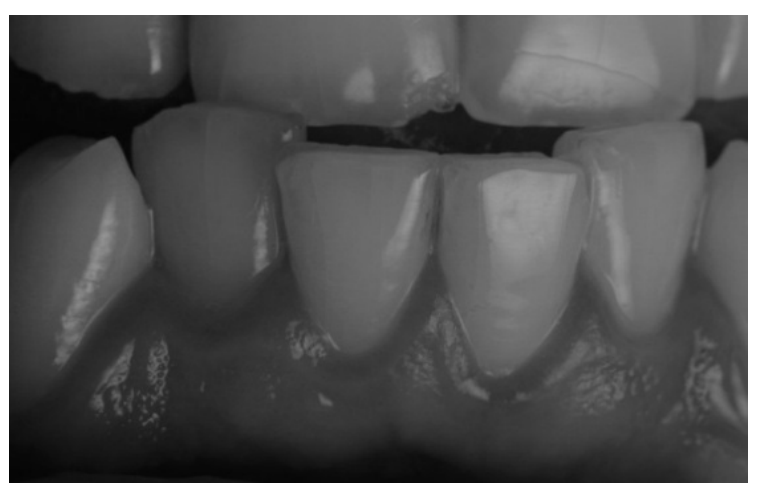

Рис. 1

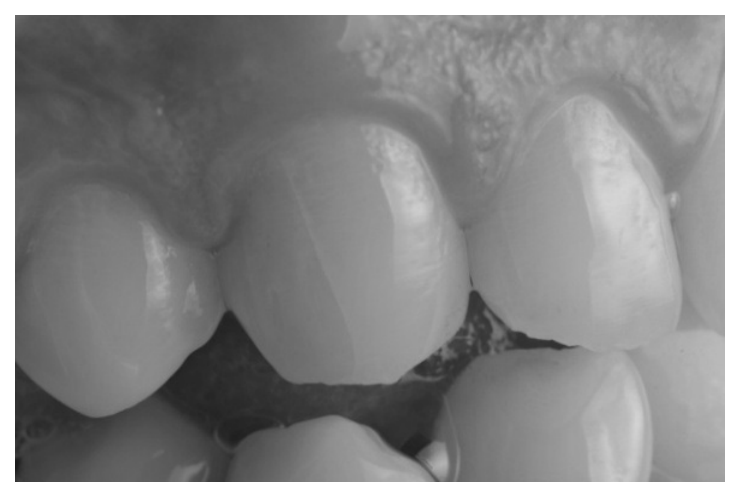

Рис. 3. 2018г

- использование увеличения с помощью дентального бинокулярного микроскопа ZumaxMedical;

- использование метода трансиллюминации, с помощью стоматологического диодного лазера Doktor smile, для выявления полных или неполных трещин, что имеет принципиально важное значение при выборе тактики лечения;

- выявление трещин эмали путём окрашивания красителями.

Осмотр поверхности эмали проводили после профессиональной гигиены полости рта, на тщательно высушенной поверхности. Пациентов разделили на 2 возрастные группы: до 30лет и после 30.

\section{Результаты исслеАования}

Типичным направлением расположения дефекта являлось продольное. Если в группе пациентов в возрасте

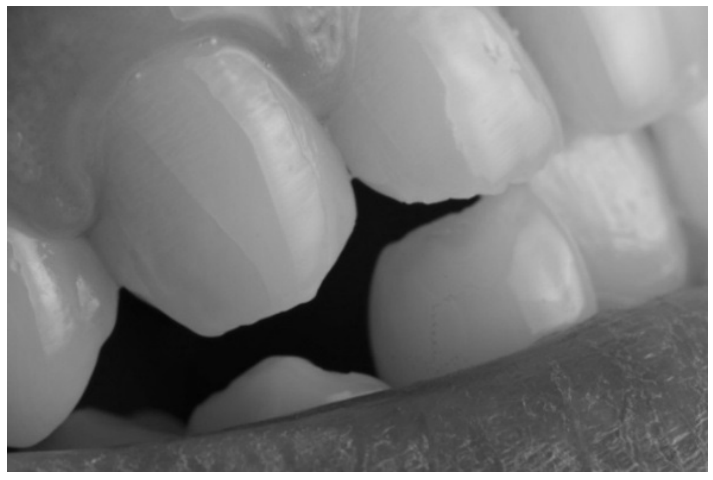

Рис. 2. 2019г

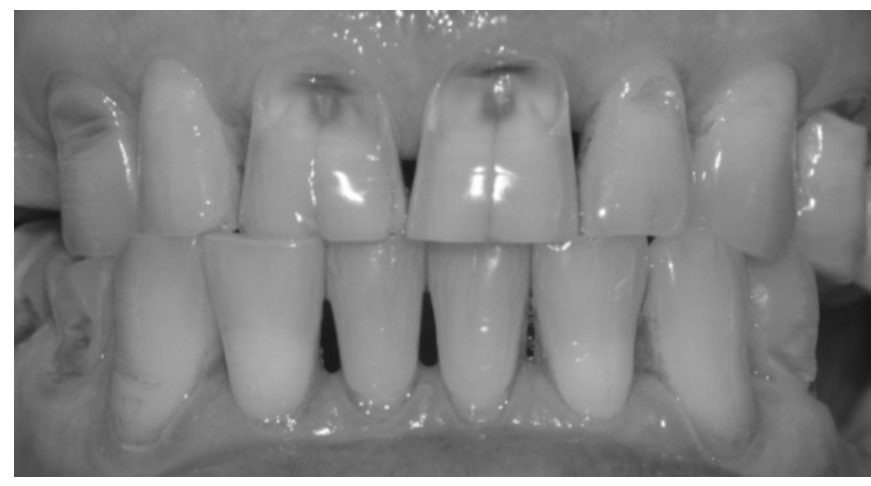

Pис. 4

до 30 лет они диагностировались только при просвечивании оптическим источником света, где можно увидеть неравномерное рассеивание света по всей структуре зуба, то в группе пациентов старше 30 лет эти дефекты можно было идентифицировать как при визуальном исследовании, так и при зондировании. Полученные данные свидетельствуют о том, что имеющиеся разрывы в структуре зуба составляют больше 36 мкм. Именно у них хорошо использовать метод окрашивания, так как пигмент с легкостью проникает в дефекты и накапливается в них. В качестве пигмента можно использовать любой краситель из арсенала врача-стоматолога. Пигмент наноси стоматологическим брашем, смываем и верифицируем линейный дефект.

В течение года лечение вертикальных бессимптомных трещин не проводилось. В результате повторного осмотра и обследования выявлен значительный прогресс трещин на протяжении года: увеличилось их ко- 
личество, протяженность (Рис. 2., рис .3.). Это связано с постоянными перегрузками вследствие нарушения окклюзии, поскольку, по различным причинам, необходимой ортодонтической помощи пациенты не получали.

У пациентов старшей возрастной группе отмечены присоединившиеся поражения эмали некариозного происхождения (клиновидный дефект), что усугубляет прогноз трещины, так как эти участки вследствие повышенной чувствительности недостаточно очищаются от налета и являются резервуаром для скапливания микроорганизмов. Рис. 4

\section{ВывO $\triangle \mathrm{b}$}

1. Выявлена высокая распространенность фрактур эмали. Пациентов с неполными трещинами эмали необходимо вести так же, как пациентов с начальными формами кариеса эмали, с соблюдением алгоритма лечения и адгезивного протокола. На сегодняшний день существуют множество препаратов для ремотерапии, но предпочтение отдается тем, которые не требуют многократного и инвазивного вмешательства, длительно фиксирующиеся на поверхности зуба, предотвращающие вымывание минеральных веществ. Пациентам с трещинами эмали рекомендуется вести мониторинг дефекта с фотофиксацией на этапах наблюдения и лечения.

2. Пациентам с нарушениями окклюзии необходима консультация ортодонта с последующей коррекцией при помощи капп или миофункциональных аппаратов, для нормализации нагрузки на зубы. Давление на зубы при жевании должно равномерно распределяться без прямых травмирующих контактов. Нормализация нагрузки на зубы и устранение суперконтактов - это этиологическое симптоматическое лечение при данной патологии.

3. Достижение трещины слоев дентина, микробная инвазия с последующим выделением ими органических кислот, способствуют образованию «дентинной раны». Необходимо выбирать методы лечения с учетом механизма возникновения дефекта - реставрация с перекрытием, это минимизирует риск растрескивания и возникновения «синдрома треснутого зуба».

Нет сравнительных данных об эффективности того или иного метода лечения линейных дефектов, каждый врач полагается на свой опыт. Ранняя диагностика и вмешательства, приводящие к стабилизации треснувших фрагментов, являются важнейшей составляющей работы врача-стоматолога.

\section{ЛИТЕРАТУРА}

1. Макеева И. М. Электронно-микроскопическое исследование твердых тканей зуба при клиновидных дефектах. /И.М.Макеева, С. Ф. Бякова, В.П. Чуев// Стоматология - 2009 г.

2. Калинина Ж. П. Характеристика основных поверхностных травматических повреждений эмали зубов. Дис. канд.мед.наук., Барнаул, 2003 г.

3. Пихур 0.Л. Состояние твердых тканей зубов у больных с двигательными дисфункциями. //Институт стоматологии.№ 1-2007 г.

(с Гендугова Оксана Мухарбиевна ( oksistom@mail.ru ), Бозиева Джамиля Султановна ( dok132813@gmail.com ), Нагоева Эльянора Анатольевна ( ertana1985@mail.ru), Хулаева Аминат Ибрагимовна ( aminahulaeva1996@mail.ru). Журнал «Современная наука: актуальные проблемы теории и практики» 